\title{
REPÚBLICA DAS MANGAS OU SOBRE 0 AMARGO GOSTO DE TUDO O QUE AMADURECE À FORÇA'
}

\section{MANGO REPUBLIC: ON THE BITTER SWEETNESS OF VIOLENT DRIVEN RIPENING PROCESSES}

\author{
Antonádia Borges*
}

\section{Introdução}

A capital brasileira, com sua peculiar arquitetura, talvez seja o símbolo mais hiperbólico de uma crença ainda vigente no modernismo. Segundo a proposta de Scott (1998), dentre outros, o olhar centrado no Estado e nas classes dominantes não raras vezes corrobora o senso comum a respeito da apatia popular. Obviamente tal juízo se torna convencional quando as lutas políticas dos governados não representam ameaça ao status dominante, ou seja, não constituem rebeliões - grandes ou peque- nas. Nesses casos, tende-se a depreciar quaisquer resistências cotidianas, a não lhes dar muita atenção. Em um de seus livros - Seeing like a State: how certain schemes to improve the human condition have failed -, Scott toma o caso de Brasília, a capital do Brasil construída nos anos 1960 sob a ideologia modernista, cujo projeto tinha, entre outros, dois propósitos específicos: (i) deslocar a administração do país do Rio de Janeiro para o interior do território, de maneira planejada, sem os vícios culturais herdados do período colonial; e (ii) conter as ondas migratórias que chegavam

*Doutora em Antropologia pela Universidade de Brasília (2003). Atualmente é Professora no Departamento de Antropologia (Brasília/DF/Brasil). Dedica-se à pesquisa em teoria antropológica, com trabalho de campo no Brasil e África do Sul. Coordena o GESTA (Grupo de Estudos em Teoria Antropológica) e, em conjunto com outras colegas da UnB, o LAVIVER. antonadia@gmail.com.

1. Artigo para o dossiê Experiências socioantropológicas através da educação. Agradeço aos organizadores, a todas as pessoas com quem trabalhei no projeto Um toque de mídias, e muito especialmente às minhas amigas e colegas Diana Milstein e Regina Coeli Machado, com quem venho nutrindo ricos debates sobre etnografia em contextos escolares. Dedico este ensaio à memória do saudoso fotógrafo José Rosa. 
ao litoral do Sudeste em busca do sonho desenvolvimentista ${ }^{2}$. A história do país fez com que à ética e à estética de Le Corbusier (inspiradora do projeto de Lúcio Costa e Oscar Niemeyer) se somasse o ideário desenvolvimentista-autoritário de uma ditadura militar que soube fazer bom uso da cidade erguida "no meio do nada" nas décadas de sua existência oficial (de 1964 a 1985).

Para não correr o risco de, como nos alerta Scott, olhar como se fôssemos o Estado e corroborar uma narrativa civilizacional opressora, temos nos dedicado a entender como jovens e crianças nascidos nas cidades do Distrito Federal brasileiro têm reivindicado uma história própria, que contesta a narrativa mestra segundo a qual a cidade se ergueu sobre uma terra de ninguém. A fim de entender como jovens nascidos no Distrito Federal olham para seu passado e seu futuro, de todas as características formais do modernismo autoritário e desenvolvimentista brasileiro desejo sublinhar neste texto apenas uma: o imenso investimento em se apagar o passado, em não se voltar para trás, em seguir adiante, e sua consequente implicação para a construção de uma memória política do país do ponto de vista daqueles cujas rebeliões intensas e cotidianas são ignoradas pelas elites dirigentes.

0 cenário de ficção científica onde nasceram os jovens com quem fiz pesquisa nos últimos anos encontra-se muito distante do Plano Piloto e dos famosos cenários da capital do "país do futuro". Nas cidades do Distrito Federal chamadas pejorativamente, ainda hoje, de "satélites", mora boa parte dos jovens que fizeram parte dos projetos de investigação que inspiram as reflexões que se seguem. Meu interesse aqui é tão somente discutir a possibilidade de, por meio da pesquisa etnográfica, suscitar outras histórias sobre esses lugares, a partir do ponto de vista e das experiências desses jovens. Meu interesse geral - a história do ponto de vista de quem nasceu numa cidade planejada de acordo com padrões modernistas, com fins quiçá velados de segregação espacial e racial -, tem raizes na pesquisa que realizei em uma das chamadas cidades-satélite, há quase vinte anos. Por isso, antes de entrar na pesquisa mais recente e em seus desdobramentos políticos e teóricos, penso ser prudente fazer um tour por Brasília, cidade singular, cujas peculiaridades marcam cada passo de minha reflexão.

Brasília, a capital do país, resume-se ao Plano Piloto e aos bairros Lago Norte e Lago Sul. Todas as outras cidades, como dito anteriormente, são chamadas de forma pejorativa de cidades-satélite. Por que pejorativa? Justamente porque, como ocorre com o termo periferia, a noção de satélite indica uma relação de dependência vital entre um centro de poder ao redor do qual gravitam não pessoas, mas "populações” inteiras. No caso de Brasília tal imagem é ainda mais impactante, pois não podemos desconsiderar que no Plano Piloto vivem os poucos e poderosos indivíduos cujos interesses, por meio dos chamados três poderes, transformam-se em "administração pública" destinada justamente "à população" (LEWANDOWSKI, 2014; CASTRO, 2013). Em Brasília, o Plano Piloto é circundando por um anel de terras não ocupadas (seria melhor

2. Usarei os termos modernismo e moderno neste ensaio de modo relativamente indistinto, embora ciente das infindáveis querelas que ambas as palavras, especialmente quando combinadas, despertam. Sem querer esgotar seus sentidos, defino tais conceitos como o fazem diversos autores, dentre os quais, Latour (2010). Para o que tenho em mãos, interessa pensar a proposta de uma cidade criada com fins civilizacionais precisos, com a imposição de uma lógica espacial e temporal mandatória, capaz de reforçar o racismo por meio da segregação e apagar a história pregressa - ou seja, a escravidão - de nosso horizonte de reflexão. 
dizer, nem ocupadas por brancos de classes abastadas nem por trabalhadores braçais) que separam a sublime capital modernista das cidades-satélite de traços igualmente modernistas, mas desprezados esteticamente. Como atestam muitos autores, os trabalhadores que construíram a nova capital foram considerados alienígenas ameaçadores quando findas as obras do Plano Piloto. Seus barracos foram derrubados, vilas inteiras postas por terra. Como "recompensa", a algumas famílias foi oferecido um lote em uma das cidadessatélite em construção. Esse processo pode ser compreendido de forma sintética, mas não menos pungente, quando descobrimos que o nome da maior cidade do Distrito Federal, Ceilândia, fundada em 1973 e hoje com meio milhão de habitantes, deriva do acrônimo CEI - Campanha para Erradicação de Invasões.

As pessoas removidas para Ceilândia e outras localidades em construção nos anos 1960 e 1970 experimentaram não apenas um deslocamento no espaço, mas também uma volta ao passado. Elas, que haviam enfrentado toda a penúria como desbravadoras e pioneiras, foram retiradas à força das cercanias do presente moderno e lançadas na obscuridade de um passado que acreditavam ter superado. Novamente, como que presas em um pesadelo, olhavam ao seu redor e o que viam era uma terra deserta, coberta de barracos, sem água, sem saneamento, sem eletricidade, sem transporte. As casas ou lotes que "ganhavam" colocavam-nas paradoxalmente em uma posição de dívida em relação àqueles que as haviam despejado e segregado. Suas demandas por direitos básicos, não raras vezes, foram qualificadas como indolência ou ingratidão.

Para quem vai pela primeira vez a Brasília, ao Plano Piloto, deve chamar atenção que em um lugar "onde não havia nada" vivam hoje quase 3 milhões de pessoas e que menos de $10 \%$ desse total more no Plano Piloto. A pergunta imediata é: onde está toda essa gente que não vejo?! A segunda pergunta poderia ser: será mesmo que não havia ninguém aqui quando a cidade foi erguida? E outra questão, relacionada à resposta dada à primeira pergunta: como é possível o ocultamento contemporâneo de mais de 2 milhões de pessoas?! Isso é especialmente intrigante se pensarmos que metade dessas não completou 20 anos de idade. Quem lê este texto pode responder: "Sim, mas isso acontece em qualquer lugar do mundo". As pessoas de verdade, os pobres, vivem nas sombras, nas periferias distantes. Ou seja,trata-se de uma pergunta tautológica para a qual já sabemos a resposta. "Por que você faz então essa pergunta?”, a leitora me indaga. Faço essa pergunta porque me interessa debater a segregação e a invisibilidade, especialmente de jovens, não somente no interior do aparato estatal (traço tão característico do modernismo à brasileira), mas também dentro da universidade onde trabalho. Como Brasília se funda sobre a invasão de terras, capitaneada por grileiros que se tornariam futuros senhores de terra e também pelo Estado, há uma dívida a ser debatida. Quem foi usurpado? A quem se deve pagar o que foi roubado?

É importante discutir portanto a forma como no Brasil - especialmente se tomamos a presença pública mais recente do país na cena mundial -, as pessoas nascem e experimentam desde a sua infância situações absolutamente não compreensíveis nem aceitáveis dentro da ideologia modernista. E mais, que a despeito de sua experiência indicar uma esquizofrenia no sistema, para que o mesmo sistema seja preservado as pessoas são arbitrariamente retiradas desse lugar de contestação, ou seja, despejadas de sua história e empurradas à força para dentro 
do modernismo, para um universal, um lugar onde são todos iguais, contemporâneos, onde a experiência pregressa pouco importa, onde o que é realmente importante é o presente e o futuro que as aguarda. É justamente esse enigma que me interessa investigar.

Em suma, embora o leitor sempre possa questionar se há mesmo algo a se extrair de uma experiência particular que se parece com tantas outras, creio que o que vivemos no Distrito Federal brasileiro traz questões importantes ao menos para refletirmos sobre nosso ofício como pesquisadores e professores no momento atual. Em nosso dia a dia, o fardo dessa perspectiva se faz notar de maneira sub-reptícia: à maioria de nós, custa olhar para o passado e reconhecer as marcas de injustiça como fardos que esmagam as pessoas à nossa frente, que as impedem de assumir a idílica posição de iguais, sonhada pelo ideário modernista que olha só para frente. Hoje, creio que pesquisas em "territórios" entendidos como "modernistas" - como é o caso de Brasília - não devam tomar o modernismo como um suposto e medir todas as formas de vida existentes ou como alinhadas ou senão como refratárias, tangenciais ou contraditórias em relação ao "modelo".

Em minha tese de doutorado (BORGES, 2004), discuti essa forma de fazer política em um território que "surge do nada", a partir da exploração do trabalho político cotidiano das pessoas. Tentei demonstrar que o Estado e os governos em Brasília foram erguidos sobre os ombros de mulheres e homens que cotidianamente alimentam uma burocracia ávida por provas documentais de sua dedicação e de seu sofrimento. Meu trabalho falava, em última instância, da intensa politização da vida local. Politização tanto em termos de conhecimento popular da máquina burocrática quanto em termos eleitorais, já que os políticos locais se utilizavam da distribuição de terras para angariar simpatizantes e beneficiar seus apoiadores. Nessa busca por novos apoios, os distintos governos mudavam a seu bel -prazer os critérios de pontuação para ordenar as listas de espera por um lote de terra. Adiante contarei uma história que conheci há pouco, na pesquisa com os jovens, e que trata justamente dos efeitos nefastos provocados por um dos critérios agregados à fórmula que procurava estabelecer quem eram os mais necessitados: a existência de alguma pessoa com deficiência na família.

Naquele cenário de pesquisa, não havia dúvidas de que as condições estruturais de dominação eram determinantes de muitas das ações dos sujeitos. No entanto, o fato de que todo mundo fazia suas próprias investigações, buscava métodos, inventava o que poderíamos chamar de teoria (embora as pessoas mesmas possam se recusar a reduzir o que produzem a esse termo que consideramos, de forma arrogante, uma tábua de salvação) indicava um espaço de agência e transformação que não poderia ser ignorado. Minha tese tinha como foco a análise das experiências de invasão de terras nas periferias das cidades-satélite, de construção de barracos, de transição das ruas de terra ao asfalto, do ponto de vista das pessoas adultas envolvidas nesses processos. Embora a tese refletisse o espírito da época, não posso deixar de lamentar tudo o que escapou de meu horizonte naquele momento, em especial uma atenção às crianças e aos jovens ${ }^{3}$.

3. A lacuna que indico não marcou apenas meu trabalho. A despeito de obras precursoras como a de Willis (1991), ou dos reiterados debates que ainda hoje ocorrem entre o legado de Bourdieu e as investigações atuais de Lahire, como identificam Szulc e Cohn (2012), na última década o reconhecimento de um espaço 


\section{Um Toque de Mídias - primeira tentativa}

No final de 2010, reuni um grupo de pesquisadores jovens (com idades variadas, em torno de vinte anos) com os quais havia trabalhado anteriormente no Recanto das Emas (BORGES; KAEZER, 2011). Desta feita, ao contrário da pesquisa anterior, os jovens não seriam objeto da investigação, mas pesquisadores. 0 grupo não era o mesmo, pois os que agora estavam no projeto eram apenas aqueles que haviam restado, isto é, que haviam conseguido começar uma carreira universitária (ainda que quase todos em faculdades privadas, pois não conseguiram furar o bloqueio e adentrar a segregada Universidade de Brasília) porque encontraram um emprego que lhes permitiu prosseguir estudando, investigando, e aprendendo a lidar com as narrativas escritas e a produção audiovisual.

Esses jovens adultos dariam oficinas de "técnicas de pesquisa" para jovens com mais ou menos 15 anos, em escolas públicas de ensino médio, cada qual em uma cidade do DF: Samambaia, Santa Maria, Planaltina, Brazlândia e São Sebastião. As oficinas seriam ministradas uma vez por mês, a cada turno em uma cidade. Para a cidade em tela, todos os demais participantes se dirigiriam com o apoio logístico do projeto, que providenciava o seu transporte. A colaboração das escolas, dos professores e dos funcionários foi imprescindivel para os casos em que o projeto caminhou bem. Os professores, por exemplo, nos ajudaram a selecionar os alunos da escola que participariam do projeto.
Posteriormente, nos demos conta do quão enviesado foi nosso critério - selecionar alunos com mais desenvoltura na escrita (e a esse ponto voltarei adiante). Sua recepção no interior da escola para as oficinas e sua disposição para fazer o que chamamos "visitas de campo" (ou seja, passeios para conhecer as cinco cidades) também foram cruciais. Essas ofıcinas mensais eram ministradas com a ajuda dos jovens bolsistas responsáveis por cada uma das cidades, ou seja, pelos pesquisadores juniores.

Além das oficinas para os estudantes de ensino médio, demos cursos mais curtos para os professores, falando-lhes de técnicas de observação e narrativa, pesquisa em arquivos e constituição de acervos, e produção audiovisual (cinema documentário e fotografia artesanal). A cada uma dessas oficinas, um dos pesquisadores seniores do grupo se dedicava com mais afınco. No grupo tínhamos, além de mim, uma historiadora, um fotógrafo e um cineasta. 0 que esperávamos dos professores era que eles se dedicassem, junto aos alunos do ensino médio que frequentavam o projeto, a produzir uma narrativa própria sobre a história (que cremos obliterada) de suas cidades, por meio das técnicas que compartilhávamos nos cursos (escrita, arquivo, vídeo e fotografia).

No processo da pesquisa, os jovens mais velhos perceberam que experiências semelhantes (do ponto de vista da narrativa modernista do Estado, centrada basicamente nas suas experiências de migração e desterro) não esgotavam o que eles próprios haviam vivido. A questão que emergiu para o coletivo de

de indagação ignorado levou inúmeras pesquisadoras a se voltarem para a investigação com crianças em si e não para outros fins ou com propósitos "prospectivos”, por assim dizer. Ilustrativos dessa guinada são os trabalhos de Pires, 2007 e 2012; Milstein, 2006 e 2008; Santillán, 2012 e Wenetz, 2011. 
investigadores foi a seguinte: "Onde colocar a ênfase?” ou "Que lado das suas histórias privilegiar?”. Vejamos, por exemplo, uma faceta da história de Mayer, um homem de 15 anos que vivia em Brazlândia. Mesmo que bem mais jovem que os investigadores juniores do grupo, ele experimentou mudanças de casa e de cidade na sua infância que replicam muitas das experiências dos jovens investigadores do projeto, moradores da cidade onde fiz minha pesquisa de doutorado. A família de Mayer, em busca de um futuro melhor, muda da cidade já "modernizada", ou seja, Ceilândia, uma cidade com infraestrutura, para uma cidade da zona rural. 0 que se passa com as crianças nessa construção de um futuro?

Eu me lembro muito bem quando nos mudamos para a zona rural de Brazlândia. Foi a primeira vez que visitei o lugar onde eu iria morar. No começo eu não gostei muito, pois gostava muito de Ceilândia, mas com o tempo fui me acostumando. Entrei em uma escola que se chamava Rodeador e nela estou até hoje. Quando eu entrei comecei a chorar, pois fiquei com medo, porque só havia mato ao redor da escola e eu pensava que se eu me perdesse ninguém iria me encontrar (informação verbal ${ }^{4}$ ).

Olhando para certos aspectos de suas narrativas, percebemos que os jovens nascidos no fim do século XX experimentam agruras similares - ao menos na forma àquelas vividas por quem é cinco, dez ou quinze anos mais velho que eles.

Uma perspectiva analítica voltada para tais aspectos de suas experiências demonstra que continuamente linhas que partem do centro, do Plano Piloto, expulsam para a periferia pessoas que passam a viver cotidianamente o paradoxo de voltar ao passado em pleno presente, de adentrar uma máquina do tempo que as empurra a um cenário onde inexistem certas "facilidades" no tocante ao que é moderno, o que os deixa revoltados: eles sabem que jovens como eles, que vivem no Plano, não combinam o presente dos computadores e celulares com o passado das ruas de barro e lama, com as noites de escuridão ou com a casinha que serve de banheiro no fundo do lote. Nisso que é próprio do modernismo fabricado em Brasília com o sangue, o suor e os sonhos de pessoas como Mayer - ou seja, o necessário retorno ao passado para aceder à prosperidade -, algumas famílias decidem por um retorno total, por voltar aos lugarejos do interior do país de onde seus velhos parentes saíram em décadas passadas, como podemos igualmente ler nesta passagem do testemunho de Shine:

No curto tempo que morei no Maranhão não consegui no início me adaptar ao lugar. As coisas eram difíceis, meu pai não conseguia emprego algum e para falar a verdade quase passei fome. Eu emagreci bastante. Eu não gostava do clima que era diferente de morar no DF (aqui faz um friozinho bom). Meu pai teve que ir para outro estado e acabou que foi quando minha mãe, eu e meu irmão acabamos voltando para Planaltina (informação verbal $^{5}$ ).

Mesmo que suas experiências se aproximem de um ponto de vista discursivo, podemos afirmar que a vida desses jovens, quando comparadas, são mais similares ou

4. Depoimento de Mayer, 2011.

5. Depoimento de Shine, 2011. 
diferentes? E de que nos vale tomar uma ou outra posição? Percebemos que o trabalho de longa duração feito com o apoio de jovens mais velhos, junto aos mais jovens, embaralhou muitas das estratégias de pesquisa que tínhamos no início do projeto. Foi justamente por causa do que saiu do script que chegamos à possibilidade de afırmar que esses jovens rechaçam os traços modernistas da história do Distrito Federal. Tal narrativa mestra não lhes diz respeito. Sua história é bem menos linear, mais criativa e, em certos pontos, até mesmo "fantástica".

Na construção dos roteiros para os documentários sobre a história de cada cidade, por exemplo, houve um afastamento total das primeiras narrativas, mais realistas, mais adequadas à narrativa modernista hegemônica a que especialmente os mais velhos (os professores e os pesquisadores seniores do projeto) estavam acostumados. Comento brevemente uma dessas mudanças para ilustrar o problema teórico com o qual passamos a lidar. No primeiro encontro que tivemos em Santa Maria, enquanto discutíamos uma abordagem narrativa que desse conta da história da cidade, emergiu uma anedota sinistra.

$\mathrm{Na}$ minha tese, eu havia escrito sobre as contínuas mudanças nos critérios que o governo utilizava para ranquear ou hierarquizar as pessoas que demandavam um lote para a construção de um barraco. Em certo governo, famílias que tivessem parentes com deficiências passaram a ser consideradas mais necessitadas. Para corrigir a fórmula a partir do novo critério, a famílias com deficientes eram dados pontos a mais. Essa mudança nas regras da política habitacional, na memória de alguns, relacionava-se a um deputado distrital, ele mesmo cadeirante e defensor dos direitos dos deficientes. 0 deputado, não por coincidência, tinha sua principal base eleitoral na cidade de Santa Maria. Como a mudança no cálculo aconteceu enquanto a cidade se erguia, muitas pessoas que foram "assentadas" na cidade tinham em sua família algum parente com deficiência. Ao menos esse era o mito.

Bem, na oficina que tivemos com estudantes e professores, construiu-se um consenso acerca do alto número de estudantes surdos nas escolas de Santa Maria. Outro rumor emergiu. Dizia-se à boca miúda que pais haviam despejado água fervente ou óleo quente nos ouvidos de suas crianças pequenas para obter mais facilmente o lote de que tanto necessitavam. Algumas pessoas na oficina ficaram chocadas. Outras, incrédulas. Outras riam muito. Só podia ser uma piada. De todo modo, como um dos "produtos" esperados pelo projeto era um documentário (curta), todos pareciam concordar que esse enredo seria um ótimo roteiro para contar a história da cidade como uma história de terror.

Lembro-me de ter compartilhado essa controvérsia com alguns colegas. Eu estava incrédula e aterrorizada. Não sabia como lidar com uma narrativa na qual os pais seriam culpados por terem ensurdecido seus filhos devido a uma pressão do governo para beneficiar pessoas com deficiência. Um colega de Portugal me deixou ainda mais deprimida: iria eu permitir que a pesquisa propusesse um vídeo no qual os pais seriam assim representados? Confesso que fiquei sem saber o que fazer.

Depois de concluída a grande oficina, os jovens investigadores começaram seu trabalho "de formiguinha" com os estudantes da escola. Nesse processo, aproximaram-se dos estudantes e, mais de perto, de Salomé. Ela lhes contou que era guitar- 
rista de uma banda de rock, que gostava de quadrinhos e de escrever canções. Dizia-se feliz, mas advertia que nem sempre o tinha sido. Quando foi viver em Santa Maria deparou-se com uma cidade onde não podia se mexer na sua cadeira de rodas. Ela tinha sido uma criança paraplégica. E, como se diz, desenganada pelos médicos. Sua condição tinha ajudado sua família a somar mais pontos e a conseguir o tão sonhado lote, no qual, ao longo dos anos, ergueram sua casa.

Depois de quatro meses do início da pesquisa, começamos a discutir coletivamente os roteiros para os curtas-metragens. Ou seja, tínhamos de finalizar "os produtos" considerando o que havia sido elaborado pelos sujeitos da pesquisa. Para minha surpresa, os estudantes de Santa Maria decidiram contar a história de Salomé como a história de sua cidade. As rodas da cadeira, assim como as rodas de outros brinquedos próprios para o asfalto e para os espaços modernizados, não se moviam em Santa Maria quando essas crianças lá foram morar. Tiveram de esperar por anos a chegada do asfalto para brincar dessas coisas. Salomé, por um milagre que ninguém tentava explicar no roteiro, gradualmente voltou a mover suas pernas e braços. Aprendeu a tocar guitarra, a cantar, a andar. 0 filme termina com um show da banda de Salomé.

Essa guinada reiterou minha postura ante as falácias dos testemunhos, das narrativas mestras que tendemos a reificar, especialmente quando estamos dedicados a pesquisas de curta duração, em que nossa intimidade com os sujeitos é pouca. Por sorte não cheguei em casa depois da oficina para escrever um paper sobre os pais que ensurdeciam os filhos com óleo fervente para ganhar um pedaço de terra; não tomei ao pé da letra aquela história nem a transformei numa narrativa fundacional, quase mítica, dos indivíduos ou da sociedade pesquisada.

Uma opressora narrativa mestra que no Brasil sublinha e aplaude o desenvolvimento modernista mascara persistentes problemas como a desigualdade e o racismo (TOSTA; ALVES, 2012). É essa narrativa que temos de desafiar. É isso que esses jovens têm nos dito em nossas investigações colaborativas. Eles têm compartilhado conosco a recusa ao insulamento de suas vidas nos escaninhos sombrios que a economia global e os mitos nacionais e desenvolvimentistas para eles destinaram. Suas teorias nos revelam a necessidade de uma nova epistemologia, de uma nova metodologia ou forma de conhecimento que realmente nos permita dizer algo de novo sobre a relação entre passado e futuro, entre trajetória e esperança (TOREN, 2010).

0 esquecimento coletivo no Brasil das condições cotidianas de existência em nome dos ideários equalizantes da democracia sob a estética e a ética do modernismo cria um cenário onde a ignorância das classes dominantes sobre a vida da maioria sustenta a ilusão de que existe igualdade e que, portanto, todos podem vir a competir em equilíbrio. Basta que existam escolas para todos. Basta que as crianças já não necessitem trabalhar porque suas mães recebem a bolsa família. Basta que o sistema único de saúde (SUS) alcance a toda gente. Para esses jovens com quem fazemos pesquisa, o modernismo do Plano Piloto e o inferno de boas intenções que o inspira nunca fizeram parte de suas vidas, marcadas pela segregação e pelo racismo (GODOY; SILVA, 2014). Para eles, tudo isso que as elites dizem lhes bastar não basta. 
0 que as escolas (nos) ensinam? ou 0 lado podre da manga

Imagino que, como muitos (falo apenas aos que gostam de manga, obviamente), a leitora já tenha tido a experiência de se sentir atraída - acho bem melhor a expressão em inglês to fall in love para falar dessa sedução - e já tenha sido seduzida por uma manga de casca reluzente, brilhante, de cor uniforme, que nos apetece só de olhar. Que tenha tido a experiência de comprá-la com avidez - na feira livre ou no supermercado - e de, no momento de parti-la, ter se dado conta de que seu interior estava podre. Que frustração! Uma manga, alguns dirão, com perdão da cacofonia e da redundância, é só uma manga. Há muitas no mundo, especialmente no Brasil, o país que seria uma verdadeira República das Mangas. Porém, o que dizer daquela saliva jorrada ao léu, daquela expectativa de lambuzar-se de néctar? Um sonho despedaçado é impossivel de se reparar. Já outras, mais sábias, saberão notar que a frustração se dá somente com aqueles e aquelas que se fiam exclusivamente em seu olhar, ou seja, que olham para a casca homogênea e se deixam seduzir pela aparente falta de imperfeições. Em suma, que a frustração se dá também pela aposta equivocada do seduzido.

Qualquer pessoa de bom senso - e conhecedora do vasto universo das mangas - sabe que a forma não garante que uma manga seja deliciosa. Essencial para aventar a hipótese de se tratar ou não de uma manga apetitosa é nosso tato, mas, especialmente, nosso olfato. Eu aprendi isso há muito tempo. Várias pessoas me falaram disso. A senhora Conchita, do mercado de Coyoacán, também conhecido como mer-caro de Coyoacán, devido aos preços proibitivos ali praticados, enfıava as man- gas pelas minhas fuças para eu sair segura de que não estava levando para casa gato por lebre. Claro, falo aqui do universo das mangas que chegam nas chamadas gôndolas dos supermercados e das feiras livres. Ou seja, de um universo no qual todas as mangas estão maduras, ou quase, prontas para, se compradas, serem consumidas por uma classe de privilegiados.

Porém, outros podem ainda acrescentar: "E o que dizer daqueles que só comem manga do pé? Que só comem manga na estação?" A relação é totalmente distinta. 0 olhar é importante, pois precisamos, lá de baixo, mirar a fruta desejada e, por meio de uma boa pontaria e de algum artefato que nos ajude a fazê-la cair, "colher" a fruta. Mas, todos sabem, na maioria das vezes ela está verde.

Quem come manga do pé gosta de manga verde. Do contrário, o melhor mesmo é admitir que não se gosta de manga. A manga verde, especialmente se for possível condimentá-la com um pouquinho de sal, é uma delícia. Mangas raramente amadurecem no pé, à espera de que as colhamos. Ou elas caem de maduras ou algum outro bicho as devora antes que sejamos nós os agraciados. De minha historinha da manga ou da República das Mangas quero destacar uma lição ou decorrência possível, a qual diz respeito à relação entre tempo e amadurecimento.

Voltando às mangas: quem tem tempo de esperar que uma manga amadureça? $\mathrm{Ou}$ melhor: quem pode pagar por isso? Quem pode pagar para comer mangas maduras?

Encerro por enquanto a parábola da República das Mangas (que a leitora, sim, entendeu bem, é uma alusão direta ao conceito derrogatório da ciência política de bistrô para se referir aos países liderados por caudilhos autoritários e elites de rapina como República das Bananas. Sim, você 
também tem razão: assim como as bananas, as mangas não são endógenas. Elas chegaram aqui junto com o imperialismo).

Passo agora a falar sobre a dialética do ser seduzido/deixar-se seduzir ou, como lhes disse, do to fall in love que, menos dualista que o par do jogo da sedução, parece aludir mais a um terceiro: o "love”, no caso, me soa como um estado, uma possessão, quase como quando dizemos em português "cair em desgraça”.

Eu caí em desgraça e me deixei seduzir por um edital da CAPES (Coordenação de Aperfeiçoamento de Pessoal de Nível Superior).

Em meados de 2010, uma pesquisadora com quem eu tinha trabalhado de forma intermitente desde 2007 no Recanto das Emas, em um projeto de pesquisa que envolvia jovens moradores da cidade, estudantes do ensino médio e jovens alunas do curso de ciências sociais da UnB, me escreveu perguntando se eu não toparia apresentar um projeto pela UnB.

Era a manga perfeita. Nem me passou pela cabeça apalpá-la, nem, muito menos, cheirá-la. Um projeto institucional - cada IFES poderia ter somente um - de grandes proporções, com recursos volumosos. Nós duas nos sentamos e fizemos um projeto, um tanto descrentes de que seríamos contempladas. Se ele não fosse aprovado, continuaríamos como antes: passando o chapéu aqui e ali e desenvolvendo nossas atividades de campo nos limites de nossos recursos e tempos.

No fim de 2010, recebemos com entusiasmo a notícia de que aquela manga era nossa. Que poderíamos degustá-la ao longo de 2011.

Ao longo de 2011, o grupo de pesquisadores que havia se consolidado no Recanto das Emas conduziu o processo de investigação narrado na seção anterior do artigo, em cinco escolas do DF, com o objetivo de produzir registros escritos e audiovisuais de histórias locais normalmente sufocadas pela narrativa modernista acachapante que grassa no Distrito Federal.

Ao projeto, ironicamente, demos o nome de Um Toque de Mídias, em alusão a Midas e aos Meios Audiovisuais, capazes, cada um à sua maneira, de transformar em ouro tudo o que tocam. Pois bem, se nos lembrarmos bem do mito do Rei Midas, agraciado por Dionísio com a capacidade de transformar tudo o que tocava em ouro, não nos surpreenderá saber o que se passou com o projeto Um Toque de Mídias.

Não tardamos a perceber que a mangacavalo-de-troia que nos foi oferecida pela Capes tinha seu interior podre. Os recursos disponibilizados pela Capes não preveem a remuneração de bolsistas, o que soa aparentemente interessante na medida em que pessoas não acadêmicas podem ser remuneradas por sua participação em um projeto de pesquisa. Eu já havia visto isso em Cape Town, no trabalho que Sophie Oldfield realiza em Valhalla Park, junto com Auntie Goet e outras pessoas. Vocês me dirão: “Até agora não vimos nada de errado com esse projeto". A seção anterior desenhava um projeto tão bem-sucedido! Digo-lhes então qual foi o problema. 0 problema do projeto teve a ver basicamente com o tempo.

Um projeto de pesquisa em escolas como a realizada pelo grupo que levou adiante o projeto Um Toque de Mídias - não pode, ou melhor, não deve ser provocador de mais expectativas frustradas. No caso em questão, as compensações, especialmente as financeiras, a meu ver, mascaram o fato de que a Capes, por meio de editais dessa ordem, de alguma maneira lava suas mãos em relação à educação básica. Ainda nos perguntamos como pudemos crer em 
um projeto e inscrevê-lo para em um ano fazer um trabalho que visa[va]

[...] a inclusão social e o desenvolvimento da cultura científica por meio de atividades extracurriculares para alunos e professores das escolas da rede pública de educação básica. As atividades deverão ocorrer nas dependências de universidades, laboratórios e centros avançados de estudos e pesquisas, museus e outras instituições, inclusive empresas públicas e privadas, visando o aprimoramento e a atualização de professores e alunos da educação básica. (trecho extraído da chamada pública $\left.{ }^{6}\right)$

Tudo de que as escolas públicas onde trabalhamos parecem não necessitar é de atividades extracurriculares. Noutra pesquisa que fiz com a professora Sayonara Leal, sobre a pertinência de nossa licenciatura na UnB para o contexto de ensino de sociologia em escolas de ensino médio, o que mais vimos foram atividades extracurriculares que são mandatórias em muitos casos e entram em rota de colisão com o volume de conteúdo previsto pelas diretrizes educacionais formuladas pelo próprio MEC (BORGES et al., 2015b).

Em publicações anteriores, procurei demonstrar como a máquina pública se apropria do trabalho daqueles que demandam benefícios dos governos, por meio da exploração ininterrupta de sua disponibilidade constante para estar a postos diante de qualquer guichê ou formulário que se lhes imponha (BORGES, 2006; BORGES, 2012). Nos espaços universitários, especialmente, mas não exclusivamente, nos projetos de extensão, uma apropriação semelhante se verifica. Apaziguados em suas consciências por conceitos como "compromisso com a comunidade", professores, estudantes e funcionários corroboram o modo regular, estatal, de produzir "saídas" para os problemas sociais, como se houvesse uma relação direta - não mediada - entre pesquisa e solução de enigmas. E mais, como se as pesquisas acadêmicas fossem mais legítimas que as não acadêmicas para o encontro de soluções para os problemas "da comunidade”. A espraiada ideia de contrapartida nos faz entender que não somos remunerados em tais ações porque tais intervenções não seriam mais que uma obrigação, dada nossa posição privilegiada. Nessa trama sórdida, aceitamos de bom grado, e até mesmo desejamos, que nosso trabalho não remunerado - ou seja, nossa mais-valia - incida diretamente sobre as frequentemente chamadas “populações”. De um só golpe esquecemos que trabalhamos para o Estado e que nossa benevolente amnésia não nos faz menos parte do Estado ${ }^{7}$.

Vejam bem, o projeto financiado pela Capes visa a que, em um ano, nós consigamos garantir "a inclusão social e o desenvolvimento da cultura científica" em uma escola na qual professores e alunos já estão assoberbados, soterrados em meio a escombros de atividades com o amargo sabor de mangas maduras que lhes são ofertadas diariamente. Vejam o quão pernicioso é todo o processo. Por um lado, a profusão de atividades extracurriculares para fomentar os chamados "novos talentos"; por outro, e

6. 0 Programa Novos Talentos foi criado pela Portaria da CAPES n ${ }^{\circ} 112$, publicada no Diário Oficial da União em 4 de junho de 2010, Seção 1, pág. 8.

7. Agradeço ao parecerista anônimo a oportunidade de esclarecer o uso que faço do termo mais-valia neste contexto específico. 
em concomitância com esse plano mirabolante, a assunção velada de um epistemocentrismo que se esconde por trás do paradoxo de se apregoar (i) a inclusão social e (ii) o desenvolvimento da ciência.

Preciso me fazer mais clara a esse respeito.

Qual a relação entre "inclusão social" e “cultura científica”? 0 projeto serviria para incluir uns e desenvolver a cultura científ1ca de outros? Ou o programa propõe que a inclusão social se dá por meio da ciência e, mais ainda, que a ciência é uma cultura?! Se for assim, eu me permito afirmar que a inclusão por meio da ciência consiste ainda hoje em um projeto epistemocêntrico em que o Outro (miserável, ignorante, sem direitos e sem talento) será ungido pela ciência e, só assim, autorizado a ingressar nos templos sagrados do saber que são as universidades em relação às escolas de ensino médio.

Vejam bem: o dia tem $24 \mathrm{~h}$ para qualquer um, inclusive para quem toma transporte público. A sobreposição de políticas públicas na área da educação, apesar de suas boas intenções, não considera justamente o quão escasso é o tempo ou, como dizia no princípio, o quanto custa para que uma manga amadureça.

Nesse contexto, a educação curricular - considerada pelos indicadores do próprio governo como precária - existe a despeito desses outros empreendimentos. A educação curricular estaria para a manga verde assim como a extracurricular para a manga de supermercado.

E nesse jogo, nós, acadêmicos, estamos sendo usados, para continuar no reino das frutas como bem o sublinhou minha colega Regina Machado em comunicação pessoal, atuando como laranjas, como testas de ferro.

Ao fim de um ano de projeto, lembrome de que, em uma tensa discussão sobre a prestação de contas, foi-me confidenciado que o dinheiro recebido do projeto servia para pagar a faculdade de pesquisadoras que antes eram elas mesmas estudantes de uma escola pública de ensino médio no Recanto e que, findo o projeto, o recurso lhes faria muita falta. Naquele momento o gosto amargo da manga madura penetrou fundo nas minhas papilas e na minha consciência. Como poderiam concluir a faculdade se o projeto iria acabar?! Naqueles anos todos de trabalho de pesquisa com os jovens adultos do Recanto das Emas, já tínhamos nos dado conta de que o sistema escolar era colonial (e tudo o que isso implica: elitista, escravocrata, racista etc.) e que, a despeito dos inegáveis talentos que as e os estudantes do Recanto das Emas esbanjavam, quase nenhum deles tinha sido aprovado no vestibular da UnB. Eles agora estavam em universidades privadas, engajados em um projeto para despertar outros jovens como eles, usando a remuneração que recebiam para pagar uma universidade privada.

Não creio que nosso problema mais premente no momento seja mais reflexividade sobre o fazer antropológico, mas uma reflexão e, se não, uma insurgência contra um Estado violento que nos agride a todas, fazendo com que "caiamos em desgraça” ao nos seduzir com os encantos de suas mangas podres, ofertadas todos os anos, a professores e estudantes de ensino médio que, quando chegam ao fim de seus cursos, têm apenas a certeza da frustração iminente a que se acostumaram depois de tantos projetos fracassados e a que sabem estar eternamente fadados. Como disse anteriormente, não podemos seguir nisso, pois um sonho despedaçado é impossível de se reparar.

Se tivéssemos encerrado nossa oficina apenas com o roteiro sobre a história de 
Salomé/Santa Maria, o desfecho deste texto seria outro. Como o projeto precisou continuar, entrando ano letivo adentro, esbarrou com a concorrência tanto de outros projetos que inundam as escolas, como de outras atividades prementes, próprias do ano letivo que chega ao final. Infelizmente o filme sobre Salomé não foi realizado ${ }^{8}$. Não soubemos nessa ocasião tornar a frustração produtiva, explorando e produzindo algo sobre o que cremos ter contribuído para a não realização do filme. Acabamos produzindo um videoclipe muito precário, em que os estudantes cantavam, em um estúdio de música, uma letra que celebrava de forma quase ufanista a cidade de Santa Maria.

\section{Um Toque de Mídias - segunda tentativa}

Não nos demos por derrotados, a despeito da frustração inicial. Do que entreouvíamos nas escolas, chamava-nos atenção como se fosse a primeira vez sempre que uma aluna ou aluno nos perguntava: "E quanto custa para estudar na UnB? Deve ser muito caro". Também ficávamos sem reação quando os estudantes diziam que jamais se inscreveriam para concorrer a uma vaga pelo sistema de cotas porque seriam eternamente acusados de ter entrado pela porta dos fundos (VALENTIM, 2012). Esses e outros ditos nos fizeram considerar a possibilidade de seguir adiante com Um Toque de Mídias. Como percebêramos que o tempo era nosso pior inimigo político e epistemológico, decidimos por fazer o trabalho desta feita em cinco escolas localizadas em uma cidade apenas: Ceilândia, a maior do Distrito Federal. A fim de refletir e agir sobre o abismo que separa as escolas de ensino médio públicas da Universidade de Brasília, resolvemos usar os espaços do campus Darcy Ribeiro e do campus Ceilândia para nossas oficinas. Essa guinada em nossa logística permitiu que alguns dos problemas anteriormente enfrentados fossem sanados. Além disso, certamente não somente pela influência do projeto, alguns dos estudantes do ensino médio que se engajaram no projeto ingressaram na UnB. A maioria deles, não.

Como dito, as atividades do projeto $\mathrm{Um}$ Toque de Mídias no interstício 2012/13 tiveram como palco cinco instituições públicas de ensino médio do Distrito Federal e envolveram alunos e professores das escolas, bem como estudantes de graduação e pós-graduação e professores da Universidade de Brasília. Tendo como interesse primordial compartilhar aspectos da área de Humanidades e Artes com educadores e estudantes que almejavam ingressar no ensino superior, desenvolvemos ao longo do período oficinas em quatro áreas: sociologia, etnografia, fotografia e audiovisual. As atividades foram se configurando a partir do cotidiano próprio de cada escola. Em algumas foi possivel reunir professores e estudantes nos mesmos horários e espaços de discussão. Em outras, especialmente em

8. A realização de um filme exigia bem mais do que supunham todas as diversas expectativas dos participantes. Na segunda edição do Um Toque de Mídias enfrentamos um desafio similar. No entanto, desta feita, fizemos das dificuldades para a finalização do filme o mote do próprio filme. Em show de pagar, mencionado mais adiante, as vicissitudes do projeto ganharam espaço no próprio material audiovisual produzido pelo coletivo de alunos e alunas. 0 confronto entre o que se cria como filme possivel e o constrangimento de meios para fazê-lo tal qual planejado (especialmente quando predominam os parâmetros estéticos das grandes corporações midiáticas) é extremamente violento. Sobre o risco da esterilidade na produção de certas "formas" de conhecimento e arte, ver o debate, tangencial ao nosso tema, de Franchetto (2008). 
função de os professores trabalharem em diferentes escolas, em ambos os turnos, as oficinas foram ofertadas separadamente, em dias desencontrados.

Os quatro eixos de nossa intervenção dialogaram mutuamente com os fins de despertar nos estudantes o interesse pelas carreiras em Humanidades e Artes (a despeito de sua predileção ou não por essas áreas), fornecer um conhecimento mais palpável sobre o funcionamento da Universidade de Brasília, propiciar um entendimento da inserção da universidade pública em suas vidas cotidianas e reconhecer as diferentes experiências de vida e interesses intelectuais dos jovens envolvidos no projeto. Quanto aos professores, a despeito das diversas áreas de conhecimento em que atuavam, ao compartilharmos técnicas de pesquisa e de produção de conhecimento (textual, fotográfica e audiovisual), pudemos construir coletivamente diversas reflexões sobre o cotidiano escolar, sobre os abismos e proximidades entre a escola e a universidade pública, chegando mesmo a despertar em muitos deles um interesse genuíno em retomar suas carreiras em cursos de pós-graduação.

Em termos de resultados substantivos, ao longo do período produzimos exposições fotográficas, ensaios em vídeo e narrativas escritas. Para além desses produtos, previstos em nosso projeto inicial, em uma das escolas (CEM 04), a pesquisa socioetnográfıca conduziu os participantes à escrita de um texto teatral e à encenação da peça, da qual participaram alunos e professores, para a comunidade escolar.

As oficinas de audiovisual foram realizadas aos sábados, dada a disponibilidade de horário tanto de estudantes e professores das escolas como da Universidade de Brasília. Delas participaram ainda o cineasta
Adirley Queirós, responsável pelas atividades, meu colega Breitner Tavares e eu, além dos estudantes da Universidade de Brasília que atuavam como monitores das atividades nesses dias e ao longo da semana, no contraturno escolar, em cada uma das escolas. Boa parte dos encontros se deu no campus da UnB que se localiza na Ceilândia, dada a proximidade com a moradia do grupo. Alguns desses encontros aconteceram no Departamento de Antropologia, no campus Darcy Ribeiro. Além das oficinas, em algumas ocasiões, promovemos após os nossos trabalhos algumas visitas guiadas a espaços da universidade até então desconhecidos dos estudantes e de alguns professores (como a Biblioteca Central, o Restaurante Universitário e a Reitoria, por exemplo).

A apresentação do projeto às escolas e o engajamento de professores e estudantes dessas escolas só se mostraram produtivos porquanto se construíram uma confiança mútua e um reconhecimento íntimo dos espaços de convívio e de existência cotidiana de ambos os grupos, a saber, as escolas e a universidade. Por essa razão mostrou-se tão importante essa possibilidade de trânsito e circulação que as escolas nos ofereceram para a concretização do projeto. Em relação a esse aspecto, é importante notar que as escolas onde trabalhamos diferiam entre si em relação a certa "inflação" de projetos de extensão e de outros tipos de cursos e estágios por lá implementados - em algumas havia muitos "projetos" e em outras, uma absoluta escassez de atividades extraclasse. Essa variável se mostrou crucial para nós, pois entendemos que a sobrecarga de projetos exige de professores e estudantes mais de seu tempo do que podem ou querem. Por tal motivo, quando fomos compartilhar os critérios de seleção dos participantes (professores ou estudantes), preferimos optar 
por pessoas que estivessem mais livres para se empenhar com afınco no projeto. Em relação aos professores, tal critério foi muito bem-vindo. Porém, estes se mostraram renitentes em engajar alunos "disponíveis" ao projeto. Segundo alguns depoimentos, alunos que não estão em algum projeto ou estágio são, por definição, pouco fiáveis. Insistimos em nossa posição, afirmando que não necessariamente os "melhores" alunos ou os mais atarefados seriam mais beneficiados com o projeto Um Toque de Mídias, tendo em vista algumas decepções em nosso ano anterior de pesquisa. Felizmente, os estudantes indicados para participar do projeto em cada escola, a despeito de algum estigma que sobre eles recaísse no princípio, tiveram um rendimento fabuloso ao longo das atividades, reelaborando em muitos casos seus anseios de vida e de futuro pessoal e profissional.

Menciono, a título de ilustração, um post "saudoso" deixado por um dos alunos no grupo Um Toque de Mídias, criado no Facebook, quando já findo o projeto: "pow sdds do curso no sábado".

0 ritmo cuidadoso nos pareceu condição sine qua non para uma inserção proveitosa de projetos do teor de Um Toque de Mídias em escolas públicas de ensino médio. Há muitos aspectos da realidade de estudantes e professores que precisam ser respeitados para que nossas atividades não se imponham de maneira autoritária e sim de modo consentido e negociado.

Antes de iniciarmos o ensino de técnicas audiovisuais no sentido estrito, procuramos familiarizar os estudantes e professores com produções de cinema independentes, contrastando-as com outras produções mais amplamente conhecidas. Ao mesmo tempo, procuramos despertar nos estudantes e professores um reconhecimento da íntima relação entre pesquisa, narrativas escritas e produção audiovisual.

Em nossos primeiros encontros no campus exibimos filmes, aos quais se seguiam debates e tarefas a serem desenvolvidas durante a semana pelos grupos de cada escola. As atividades ao longo da semana eram acompanhadas pelos monitores (estudantes de graduação da UnB), nas próprias escolas. Nos encontros nas escolas reconhecemos que, para além das atividades propostas, era gerado um debate sobre o acesso à Universidade (a qual muitos, incluindo professores, tinham passado a frequentar apenas após o engajamento no projeto), sobre a convivência na UnB com estudantes e professores de outras escolas e estudantes e professores universitários. Esses encontros no campus e nas escolas ensejaram reflexões sobre diferenças territoriais importantes para a condução posterior das atividades do projeto. Após uma familiarização com diversas produções, os alunos e professores foram convidados a refletir sobre as condições de sua produção, ou seja, sobre o trabalho necessário para se colocar na tela a ideia seminal de um roteiro, seja de ficção ou documental.

As atividades propostas conclamavam estudantes e professores a pensar nas camadas de realização de um filme, nas várias mãos em cooperação, produzindo inicialmente uma fragmentação do filme visto como uma massa homogênea, a fim de reconhecer os vários agentes envolvidos em sua fabricação. Essa reflexão sobre o audiovisual evocou em todos os casos a complexa composição do conhecimento nas escolas. Assim, lentamente, com exercícios que iam da caracterização dos personagens (compondo assim uma preocupação com aspectos de arte) à composição sonora das cenas imaginadas (configurando um núcleo 
de som), passando por vários outros aspectos (uso de câmera fotográfica e produção de fotonovela, desenhos, redações, entrevistas, pesquisa em arquivo, construção de histórias de vida), estudantes e professores se dividiram em áreas de conhecimento específicas e passaram a se envolver mais detidamente com as áreas de direção, de fotografia, de dramaturgia, de som, de arte e também de produção.

A partir dessa separação do grupo em unidades especializadas, passamos a desenvolver atividades específicas. A separação levou a uma especialização da formação e, em última instância, ao aprimoramento de talentos evidentemente existentes entre os membros de cada equipe, cada qual composta por pessoas ora com afinidade ora com alguma vivência prévia - mesmo que amadora - em elementos de direção, de composição de roteiro, de direção de arte ou de fotografia, ou mesmo em composição sonora.

Nessa nova fase das oficinas, é importante destacar que houve uma maior aproximação entre as pessoas das diversas escolas participantes, tendo em vista que cada núcleo reunia indivíduos de escolas distintas. A proximidade e o convívio despertaram novas reflexões sobre a política territorial de segregação racial e de classe que perpassa a vida de quem frequenta a universidade e a escola pública, incitando férteis debates sobre diferença e tolerância que renderam frutos muito positivos ao longo dos meses de trabalho coletivo.

Nem todos os estudantes e professores das escolas onde trabalhamos compartilham a mesma trajetória ou o mesmo dia a dia; há diferenças extremas em seus cotidianos, em suas memórias e em suas aspirações. Conflitos familiares, violência doméstica, racismo, problemas financeiros, anseios profissionais e afetivos, inquieta- ções religiosas e inúmeras outras "chaves analíticas” reúnem de forma meramente esquemática as inúmeras nuances de suas vidas (THIN, 2006).

Por essa razão foi se desenvolvendo uma reflexão sobre a necessidade de se promover um conhecimento verdadeiramente complexo que se opusesse ao olhar mais desavisado que pode em princípio achatar essas diferenças, tornando plano um relevo de relações que, a despeito de ser acidentado, oferece pistas importantes para pensarmos uma renovação nos meios de ensino existentes em nossas instituições. Para ilustrar tal relação e suas implicações, mencionamos os diversos diálogos que mantivemos com pais, mães e outros responsáveis pelos alunos, tanto no momento em que pedimos seu consentimento informado quanto ao longo do projeto. Nessas trocas periódicas fomos interpelados por preocupações genuínas dos responsáveis por seus filhos e filhas, indicando no mínimo algumas implicações sobre a presença do projeto no interior das casas e na vizinhança dos estudantes envolvidos.

As diferenças entre cada sujeito responderam ao longo do processo por reações diversas em relação ao ambiente da $\mathrm{UnB}$, onde se davam as atividades coletivas. Essas reações - de admiração e sensação de bem-estar, e de rechaço e reconhecimento de violentas barreiras simbólicas -, eram debatidas nos encontros semanais que aconteciam nas escolas e em conversas informais entre os participantes do projeto. Dentre os inúmeros debates realizados, ficou patente o quanto a universidade pública, apesar de muitos discursos aparentemente devotados à inclusão social, ainda continua refratária a uma mudança radical em sua paisagem social. Entre as diversas localizações dos preconceitos e da intole- 
rância mútua, especialmente em meio aos jovens, ficou patente a importância do gosto musical e da produção da indumentária na construção de identidades - algumas em diálogo e algumas imisciveis.

Aparentemente, nessa fase da vida em que ainda não concluíram o ensino médio, trabalhando algumas vezes em empregos temporários e precários, os jovens apostam em uma definição de quem são e daqueles com quem gostam de estar a partir da música que escutam, das coreografias que dançam e das vestimentas que marcam a sutileza entre eles e os outros. Dessa reflexão surgiu de um dos estudantes vinculados ao projeto a ideia-mestra para um dos filmes produzido pelas escolas envolvidas. 0 filme Show de pagar gira em torno da rivalidade entre funk, pagode e rock, emblemática de embates envolvendo questões raciais, de classe, de sexualidade e de gênero.

As oficinas de fotografia ministradas pelo fotógrafo José Rosa, por sua vez, ocorreram em cada escola separadamente, envolvendo professores e alunos, que acudiram às aulas no contraturno escolar. Inicialmente houve debates promovidos pelo fotógrafo, com o auxílio de monitores estudantes da Universidade de Brasília, acerca da fotografia como objeto estético e narrativo. Dada a familiaridade de muitos dos envolvidos com instrumentos digitais que fotografam - como celulares -, o maior desafio aqui foi sustentar a proposta de expandir as possibilidades da fotografia para além dos limites conhecidos. Nas oficinas, técnicas foram compartilhadas e sua aplicação se deu de maneira mais produtiva no exercício de pinhole, quando professores e estudantes produziram fotografias artesanais em preto e branco, atuando no processo da captação à revelação das fotos. Algumas das fotografias foram posteriormente selecionadas pelo grupo e impressas em formato maior, compondo uma exposição fotográfica inicialmente exibida no campus da UnB em Ceilândia e, posteriormente, em cada uma das escolas participantes. A exposição fotográfica na UnB aconteceu quando da realização da Semana Acadêmica, ocasião em que promovemos também uma mesa-redonda com a participação de estudantes e professores das escolas envolvidas, a respeito do projeto Um Toque de Mídias. Cabe frisar que, às moscas nessa semana, a universidade não cumpriu seu papel de acolher a comunidade que a ela se dirigiu, nessa data especial, para ver como é a vida supostamente vibrante naquele ambiente.

Já as oficinas de pesquisa em antropologia e sociologia foram ministradas por mim e pelo professor Breitner Tavares, nós dois da UnB, nas cinco escolas engajadas no projeto. As oficinas começaram com discussões amplas sobre a pesquisa sociológica e antropológica, quando compartilhamos por meio de apostilas nossa própria produção com professores e estudantes das escolas. 0 interesse despertado por nossas atividades de investigação anteriores, pelos artigos que escrevemos e disponibilizamos nas apostilas, abriu caminho para o projeto Um Toque de Mídias, afinal, nosso interesse presente ancorava-se em uma trajetória mais longa de pesquisa com questões irmanadas àquelas que ora apresentávamos aos diretores, coordenadores, professores e estudantes das diferentes escolas.

Promovemos em seguida debates em torno de alguns métodos ou abordagens que amenizam as dificuldades da pesquisa em ciências sociais. Tratamos de discutir noções de escala, de significância, de generalização, de transitoriedade (tempo) e abrangência (espaço), a partir de algumas 
técnicas como a entrevista (questionário, survey, história de vida, relato), a pesquisa documental (acervo e registros pessoais ou institucionais) e a observação com interesse etnográfico. Em cada oficina buscamos despertar nos participantes um interesse pela vida alheia, pelo companheiro ao lado (fosse este estudante ou professor). 0 resultado desses "encontros investigativos" foi admirável; a despeito do convívio cotidiano intenso, muitas pessoas se revelaram surpresas com aspectos da vida daqueles e daquelas de quem se consideravam íntimas e, em outros casos, dadas as descobertas sobre alguém a respeito de quem não se nutria maiores interesses, novas relações de amizade e troca foram estabelecidas, e laços estreitados (SEFFNER, 2011).

0 exemplo mais evocativo desse processo se deu com a construção coletiva da peça teatral Doralice. 0 texto surgiu a partir das oficinas de socioetnografia, e retratava o cotidiano de uma professora que, em alguma medida, apesar do caráter ficcional da obra, sintetizava aspectos da vida de todos os professores e professoras da escola. Quando de sua encenação, em larga medida em função de seu caráter jocoso, professores e estudantes da plateia não somente se surpreenderam com o talento dos colegas no palco, mas com a natureza das questões por eles trazidas a uma arena pública de apreciação e discussão.

\section{Conclusão: entendimento e admiração mú- tua como ponte para aproximar Escola e Universidade}

Esses movimentos de circulação dos jovens e professores das escolas na universidade e de mergulho em suas interações mais intimas e cotidianas levaram o grupo como um todo a desenvolver debates subs- tanciais a respeito do papel da universidade pública em suas vidas. Mais do que promover a UnB como panaceia para todos os males, pareceu a todos mais prudente e pertinente problematizar a universidade como ela existe e se faz presente na vida do Distrito Federal, em suas contribuições, mas também em seus limites e sua negligência em relação à vida local.

Essas forças de atração e de repulsão da universidade puderam ser bem percebidas no desenvolvimento do filme e das fotografias produzidas ao longo do projeto. No filme, algumas cenas se deram nas casas dos participantes, nas ruas da cidade e também nos corredores da UnB. Aparentemente, vemos um investimento claro por parte dos estudantes e professores na produção de um objeto de conhecimento e arte que borra as fronteiras entre o espaço acadêmico e a vida cotidiana. Entretanto, dada a forma de acesso ainda restrita e bastante elitizada aos bancos universitários, estudantes e professores das escolas de cidades periféricas como aquelas onde desenvolvemos o projeto sabem o quão pouco provável é seu ingresso e, quanto ele acontece, sua permanência em instituições universitárias públicas como a UnB.

Ainda que não houvesse muitas das demais razões acima elencadas, apenas por esta - problematizar a ética e a estética dominantes nas universidades públicas de nosso país e o persistente rechaço a outras formas de conhecimento e arte que existem, a despeito dos cânones, fora dos muros acadêmicos -, já garantiríamos o sucesso do projeto Um Toque de Mídias, recebido com grande entusiasmo em escolas onde professores e estudantes tinham as mínimas condições - institucionais e pessoais - de transformar seus cotidianos de trabalho, ensino e aprendizagem a partir do que propusemos. 
Como fazem esses professores e estudantes, devemos aprender a abrir brechas em nosso dia a dia para experimentar outras formas de conhecer e de transmitir conhecimento, para além daquelas a que estamos habituados. Assim como as escolas têm nos acolhido com cortesia, quando nossa chegada não é por demais violenta, por demais estatal, também a universidade e outras instituições superiores de ensino e pesquisa em nosso país precisariam abrir seus braços e suas mentes para a incorporação do novo que, no caso da escola pública, coincide com o que foi sempre indesejado pelas elites e considerado improvável pelas estatísticas.

As políticas de reserva de vagas em curso e em expansão precisam levar em conta a experiência particular do Distrito Federal brasileiro. Aqui, como desenhei no começo do ensaio, um projeto modernista se impôs à força, a partir do mito da terra de ninguém. 0 suposto desenraizamento de todos que chegaram e chegam a Brasília produziria em si certa igualdade. Ora, o que procurei narrar nas linhas precedentes foi justamente as venturas e desventuras de um projeto de extensão que se encontrou constantemente confrontado com os paradoxos e a violência desse mito fundador. Em Brasília os senhores ainda ocupam a casa-grande. A tal ponto que o Ministério da Educação, dando-se conta das pequenas chances de ingresso de estudantes advindos de escolas públicas de educação fundamental em carreiras tidas como científicas, propõe um edital a fim de que professores universitários busquem saídas para tal problema em projetos de extensão. Esquecemo-nos (nós da academia e também nossos colegas técnicos do governo) de que tanto professores quanto alunos da educação básica em escolas públicas continuam sendo usurpados, a exemplo de uma persistente escravidão.

Sem nossa autorreflexão e escuta atenta aos sinais com que nossos interlocutores nos brindam, corremos o risco de entrar nas escolas com possíveis cavalos de Troia, ou seja, projetos que, ao invés de reparar as perdas históricas, acabam por drenar ainda mais o escasso tempo político e epistemológico daqueles que nos acolhem. A noção de tempo aqui empregada deve ser portanto compreendida a partir das reservas que estabelece em relação a outras abordagens ${ }^{9}$. 0 tempo de que falo não pode ser entendido como uma categoria social de entendimento como sustenta Durkheim. Tampouco como fenômeno extrínseco e igualmente inexorável a todas as criaturas, como se costuma formular o tempo cronológico. Quando afirmo que aos pesquisadores que aterrissam em escolas "sobra tempo”, quero sugerir que sua associação com aquele lugar, com aquelas pessoas e suas vicissitudes difere do envolvimento e compromisso de seus anfitriões (BORGES, 2009). Essa seria uma evidência quase "concreta" da divisão entre "nós” e "eles". Ter mais ou menos tempo, nesse caso, seria equivalente a dizer ser mais ou menos Outro. Minha proposta de etnografia popular visa justamente a problematizar a noção de alteridade e sua relação direta com a antropologia colonial, racista e predatória a que nos dedicamos (BORGES et al., 2015a). Em suma, creio que seja chegada a hora de todos os que estão dentro dos muros universitários dedicarem seu tempo para colocar o muro abaixo, para inventar o novo, em que a divisão e o abismo não sejam sequer lembranças. 


\section{Referências}

BORGES, A. Tempo de Brasília:. etnografando lugares-eventos da política. Rio de Janeiro: Relume Dumará, 2004.

BORGES, A. 0 emprego na política e suas implicações teóricas para uma antropologia da política. Anuário Antropológico, Rio de Janeiro, v. 2005, p. 91-125, 2006.

BORGES, A. Explorando a noção de etnografia popular: comparações e transformações a partir dos casos das cidades-satélites brasileiras e das townships sul-africanas. Cuadernos de Antropología Social, v. 29, p. 23-42, 2009.

BORGES, A.; KAEZER, V. 0 Recanto dos Meninos. MILSTEIN, D. et al. Encuentros etnográficos con niñ@s y adolescentes. Entre tiempos y espacios compartidos, Buenos Aires: Miño y Dávila, 2011.

BORGES, A. Ser Embruxado: notas epistemológicas sobre razão e poder na antropologia. Civitas: Revista de Ciências Sociais, v. 12, p. 469-488, 2012.

BORGES, A. et al. Pós-Antropologia: as críticas de Archie Mafeje ao conceito de alteridade e sua proposta de uma ontologia combativa. Sociedade e Estado, v. 30, p. 347-369, 2015 a.

BORGES, A. et al. Faça o que eu digo, mas não faça o comum: uma reflexão acerca da prática etnográfica voltada para a compreensão do itinerário do ensino de Sociologia dos bancos acadêmicos ao interior das escolas brasileiras. In: HANDFAS, A.; MAÇAIRA, J.; FRAGA, A. (Orgs.). Conhecimento Escolar e Ensino de Sociologia: instituições, práticas e percepções. Rio de Janeiro: 7 Letras, p. 295-307, 2015b.

BOURDIEU, P. A escola conservadora: as desigualdades frente à escola e à cultura. Educ. Rev. n. 10, p. 5-15, 1989.

CASTRO, M. S. M. de. A integralidade como aposta: etnografia de uma política pública no Ministério da Saúde. 201. 343f. Tese (Doutorado em Antropologia Social), Universidade de Brasília. Brasília, 2013.
FRANCHETTO, B. A guerra dos alfabetos: os povos indígenas na fronteira entre o oral e o escrito. Mana, Rio de Janeiro, v. 14, n. 1, abr. 2008.

GODOY, M. E. C.; SILVA, R. C. M. "Lá embaixo": percepções da criança de uma escola pública sobre o cotidiano do bairro onde vive, do lado brasileiro da fronteira. Línguas \& Letras, UNIOESTE, v. 15, 2014.

LAHIRE, B. Crenças coletivas e desigualdades culturais. Educ. Soc., Campinas, v. 24, n. 84, p. 983995, set. 2003.

LATOUR, B. An Attempt at a "Compositionist Manifesto”. New Literary History. Volume 41, Number 3, p. 471-490, Summer 2010.

LEWANDOWSKI, A. 0 direito em última instância: uma etnografia do Supremo Tribunal Federal. 2014. 227f. Tese (Doutorado em Antropologia Social), Universidade de Brasília, Brasília, 2014.

MILSTEIN, D. Conversaciones y percepciones de niños y niñas en las narrativas antropológicas. Sociedade e Cultura, v. 1, n.1, 2008.

MILSTEIN, D. Y los niños, ¿por qué no?: algunas reflexiones sobre un trabajo de campo con niños. Avá, Posadas, n. 9, ago. 2006.

PIRES, F. Crescendo em catingueira: criança, família e organização social no semiárido nordestino. Mana, Rio de Janeiro, v. 18, n. 3, dez. 2012.

PIRES, F. Ser adulta e pesquisar crianças: explorando possibilidades metodológicas na pesquisa antropológica. Revista de Antropologia, v. 50, n. $1,2007$.

SANTILLÁN, L. Quiénes educan a los chicos? Infancia, trayectorias educativas y desigualdad. Buenos Aires: Biblos, 2012.

SCOTT, J. C. Seeing Like a State: How Certain Schemes to Improve the Human Condition Have Failed. New Haven, CT: Yale University Press, 1998.

SEFFNER, F. Um bocado de sexo, pouco giz, quase nada de apagador e muitas provas: cenas escolares envolvendo questões de gênero e sexualidade. Revista Estudos Feministas, v. 19, n. 2, 2011. 
SZULC, A.; COHN, C. Anthropology and Childhood in South America: Perspectives from Brazil and Argentina. AnthropoChildren, Issue 1, jan. 2012.

THIN, D. Para uma análise das relações entre famílias populares e escola: confrontação entre lógicas socializadoras. Revista Brasileira de Educação, v. 11, n. 32, maio/ago. 2006.

TOREN, C. A matéria da imaginação: o que podemos aprender com as ideias das crianças fijianas sobre suas vidas como adultos. Horizontes Antropológicos, Porto Alegre, ano 16, n. 34, p. 19-48, jul./dez. 2010.

TOSTA, S.; ALVES, P. Cultura e cor na escola: uma etnografia com adolescentes negros de elite. In: DAUSTER, T.; TOSTA, S.; ROCHA, G. (Orgs.). Etnografia e educação: culturas escolares, formação e sociabilidades infantis e juvenis. Rio de Janeiro: Lamparina, 2012.

VALENTIM, D. F. D. Ex-alunos negros cotistas da UERJ: os desacreditados e o sucesso acadêmico. 2012, 234f. Tese (Doutorado em Educação). Pontífice Universidade Católica, Rio de Janeiro, 2012.

WENETZ, I. Das escolhas que fiz: implicações etnográficas na pesquisa com crianças. Pro-Posições, Campinas, v. 22, n. 2 (65), p. 133-149, maio/ ago. 2011.

WILLIS, P. Aprendendo a ser trabalhador: escola, resistência e reprodução social. Porto Alegre: Artes Médicas, 1991. 
RESUMO

0 presente ensaio narra as venturas de um projeto de extensão da Universidade de Brasília, voltado para a pesquisa etnográfica em colaboração com estudantes e professores universitários e de escolas públicas de ensino médio no Distrito Federal. Estimulado por um edital de fomento que visava à “[...] inclusão social, [...] [ao] desenvolvimento da cultura científica [e ao] aprimoramento e [à] atualização de professores e alunos da educação básica", Um Toque de Mídias provou o amargo sabor de certa inflação de projetos que soterra algumas das escolas que conhecemos. Ao longo de cinco anos, tivemos elementos e tempo para refletir sobre os limites da proposta inicial. Na segunda edição do projeto, ensaiamos algumas soluções para os becos sem saída experimentados na primeira fase. Percebemos a urgência de se reconhecer o abismo que separa a escola da universidade pública, de torná-lo conhecido de todos e de repensar propostas paliativas que dificilmente encaram o racismo e a desigualdade como desafios cruciais.

\section{PALAVRAS-CHAVE}

Etnografia. Escola. Extensão. Educação Básica. Brasília.

\section{ABSTRACT}

In this essay a testemonio is given on an Extension Programme led by the author at the University of Brasília, between 2010 and 2014. The project was sponsored by a governmental fund which target was "to promote social inclusion, the development of a scientific culture, the betterment and updating of basic education students and teachers". Along the following lines we narrate some challenges our research group has faced in its first year of activity. Subsequently we give a deep thought on a former hidden subject to which we have decided to emphasize in our last and second period of research: the gap that still exists between public schools and university in Brazil. We propose issues like racism and inequality should be part of our agenda in spite of project's specificities.

\section{KEYWORDS}

Ethnography. School. Extension. Basic Education. Brasília. 